\section{MOTILITY IN CELLS}

\section{Aspects of Cell Motility}

Edited by P. L. Miller. (Symposia of the Society for Experimental Biology, No. 22.) Pp. vii +370. (Cambridge University Press: London, September 1968. Published for the Company of Biologists on behalf of the Society for Experimental Biology.) $85 s$.

THE preface of this very good volume with its hopefully omnium-gatherum title rightly asserts that there is more than a hint that motility in both muscular and nonmuscular cells is dependent on a contractile apparatus of similar constitution. The concepts, models and techniques which have so elegantly illuminated the role of actin and myosin in muscular contraction are now beginning to be used to help in our understanding of the motility of nonmuscular cells.

Some of the articles are excellent in that they include hunches brilliantly supported by fresh evidence. Others reaffirm what is already well known, while a few articles take a slightly cavalier line with debatable points and with scarcely a reference to actin-myosin interactions or sliding mechanisms. Certain preoccupations recur.

The first five articles of the eightcen are concerned with the classical structural concept of muscular contraction. The opening article by S. V. Perry is authoritative, and by immediately referring to myosin-like proteins being also present in a wide variety of non-muscular cells it brings into the limelight the underlying reason for the symposium. The effectiveness of the myosin molecule to interact both with actin and with itself to develop and transmit tension along the myofibril is clearly portrayed. A. Szent-Györgyi provides a stimulating article. Fresh experiments show how heavy meromyosin in the interaction with actin may exist in two different states or shapes dependent on nucleotide association. The ability of this molecule to change its conformation is echoed in the interesting suggestion made in J. W. S. Pringle's article that the generation of mechanical energy is based on an active change of angle of attachment of the myosin molecule to actin. J. C. Ruegg confirms that the contractile system of smooth muscle is basically similar to that of striated muscle, and R. J. Podolsky reaffirms that the withdrawal of calcium from the contractile elements is involved with muscular relaxation.

Picking and choosing from the remaining highly specialized articles have been influenced by an attempt to trace the extent to which the present tenets of muscle contraction have found a place in other systems. The sliding-filament model is used by C. J. Brokaw to explain the helicoidal movement of sperm flagella, and by M. A. Sleigh the beat of cilia. A. Bajer describes chromosome fibres "sliding" along continuous fibres to account for chromosomes moving towards opposite poles during mitosis. The movement of non-flagellate spermatozoa seems to be brought about, according to the finding of B. L. Gupta, by the conventional method of producing "undulating waves" generated by contractile bands. N. Kamiya from his studies on glycerinated specimons of a myxomycete is drawn into suggesting that actomyosin-type proteins are associated with the movement of the plasmodium. R. D. Allen sees amoeboid movement as embracing a consortium of complicated processes.

E. J. Ambrose and J. A. Forrester conclude that the undulating contact of the surface of a fibroblast cell is responsible for the cell "crawling" over a glass surface. Increasing the negative charge at the surface of the cell causes the surface to expand; decreasing the charge has the opposite effect. Does this signify that altering the surface charge affects the contractile actomyosin system of the fibroblast? L. Wolpert and D. Gingell develop the eonception of the electrostatic surface potential being part of a sort of "sensory" mechanism through which external stimuli evoke a response by the cell.

The articles which have not been mentioned are equally fascinating. All of the articles are valuable, and their value is enhanced by being published in a single volume. With the evidence for the presence of actomyosin-like proteins within and at the periphery of non-muscular cells accumulating, it may well turn out that the locomotory activity of many of these cells stems from the interaction of actin and myosin.

BRYN M. JoNes

\section{NEW GUINEA FISHES}

\section{The Fishes of New Guinea}

By Ian S. R. Munro. Pp. xxxvii $+650+84$ plates. (Department of Agriculture, Stock and Fisheries: Port Moresby, New Guinea, 1967.) n.p.

Although there have been two principal ichthyological works which include the New Guinea area in their compass, The Fishes of the Indo-Australian Archipelago, by Weber and De Beaufort (1913-53), and Fowler's The Fishes of Oceania (1928-49), neither could be considered a handbook suitable for non-specialist use. It is the author's expressed intention to produce just such a book and, with some compromise, one which would also serve as a technical treatise for the zoologist. I believe that he has succeeded in this difficult task, even if the balance dips somewhat in favour of the non-specialist.

Because the emphasis is placed on identification, Munro has paid special attention to producing adequate keys. Keys are provided for orders, suborders, families and species, but not genera; the thorough glossary of basic morphological and descriptive terms should enable a non-specialist quickly to master their use. Short, confirmatory diagnoses are given for each category keycd out; the species' descriptions include notes on live coloration. Most species are illustrated (a few in colour). The figures are rather small, but should be adequate as visual backing for the more quantitative information given in the descriptions. Most of the figures are grouped together in a series of plates bound into the back of the book. This arrangement could be something of a drawback in practice, although it does allow for rapid scanning if a preliminary identification is to be made by sight. Munro is a realist: he includes instructions on how to identify a fish by using the illustrations.

Wherever possible the author gives local vernacular names for the species, and he has gone to great pains to provide English common names for all species. One cannot help wondering if this was really necessary; somehow the name "Cock-up" (Lates calcarifer) has a ring of authenticity, but "Arafura Eyebrowfish" (Psenes arafurensis) savours more of the pedant than the field-worker. All in all, the non-specialist is well provided for. The specialists, too, should have few complaints, especially because Munro's earlier check-list (1958) will fill many of the gaps which were of necessity creatcd in this more general work. Particularly does this apply to questions of nomenclature and synonymy. One omission which both specialist and non-specialist will notice is the lack of details on the geographical distribution of those fishes which also occur outside the New Guinea area. Likewise it would be holpful to know when certain characteristics used in the general discussions and in the diagnoses apply only to the species occurring in the area covered by the book. For example, the statement that catfishes are "mainly estuarine but some are permanent inhabitants of fresh water" is undoubtedly true for New Guinea, but it is the reverse of the actual situation among the Siluriformes as a whole.

One section I would single out for particular criticism- 